\title{
Review
}

\section{Regulation of death receptor signaling by the ubiquitin system}

\author{
IE Wertz ${ }^{*, 1}$ and VM Dixit ${ }^{2}$
}

The study of death receptor (DR) signaling has led to the discovery of new signaling paradigms, including the first example of direct receptor-mediated activation of a protease (caspase-8) that functions as a second messenger to initiate a 'death cascade' of downstream protease activation. More recently, this receptor system has underscored the importance of ubiquitin modification in NF- $\kappa$ B activation. Both degradative lysine 48-linked polyubiquitin and scaffolding lysine 63-linked polyubiquitin have an essential role in signal propagation. Remarkably, a negative feedback process, termed ubiquitin editing, regulates signaling that emanates from certain DRs. Ubiquitin editing is mediated by a complex interplay between the ubiquitination and deubiquitination machinery, resulting in the replacement of signal enhancing lysine 63-linked polyubiquitin with signal extinguishing lysine 48-linked polyubiquitin. The ubiquitination machinery and its regulation in the context of DR signaling are discussed herein.

Cell Death and Differentiation (2010) 17, 14-24; doi:10.1038/cdd.2009.168; published online 6 November 2009

The tumor necrosis factor receptor (TNFR) family is characterized by the presence of a variable number of cysteinerich domains within the extracellular segment and includes receptors known as the death receptors (DRs). The cognate ligands function in concert with the receptors to orchestrate immune responses, generate secondary lymphoid organs, and modulate the survival, proliferation, and differentiation of responding cells. When this axis goes awry, it can contribute to sepsis, cachexia, and autoimmune disorders including rheumatoid arthritis, inflammatory bowel disease, and psoriasis. ${ }^{1,2}$ Indeed, therapeutics based on neutralization of tumor necrosis factor- $\alpha$ (TNF- $\alpha$ ) have met unparalleled success in the treatment of many autoimmune disorders. Furthermore, there has been a recent groundswell of enthusiasm for exploiting the proapoptotic properties of the DRs for TRAIL/ Apo2 ligand that selectively mediate the demise of tumor cells.

There are six TNFR family DRs identified in humans to date: Fas/CD-95, TNFR1, DR3, DR4, DR5, and DR6. They are characterized by the presence of an $\sim 80$-residue motif within their cytosolic segments dubbed the death domain (DD). ${ }^{1,2}$ The integrity of this domain is essential for engaging downstream signaling components that, depending on the cellular context, promote either prosurvival and proinflammatory signaling pathways or promote apoptosis. ${ }^{1,2}$ The DD is sixhelical fold that adopts a 'Greek key' topology and mediates homotypic interactions. There are four death-fold motifs: the DD itself, the death effector domain (DED), caspase activation and recruitment domain (CARD), and the Pyrin domain. ${ }^{3}$
Although these folds all possess a similar topological configuration, their surface charge is distinct such that specificity of association is dictated by electrostatic interactions. $^{3}$

The DRs initiate signaling by recruiting one of two DD-containing platform adaptor molecules: FADD (Fas Associated Death Domain) that generally mediates apoptosis and/or TRADDD (T̄NF Receptor Associated Death Domain) that engages both apoptotic and nonapoptotic signaling pathways. These adaptors in turn recruit distinct signaling complexes that mediate the downstream signaling events. FADD, for example, has a bipartite architecture - containing both a DD that allows for receptor binding and a DED that enables recruitment of the proapoptotic caspase- 8 and $-10 .^{4}$ Both caspase- 8 and -10 contain a DED embedded within their prodomains, thus a DED-DED homotypic interaction is responsible for the engagement of these proapoptotic apical caspases. ${ }^{4}$ The TRADD adaptor recruits a DD-containing kinase termed Receptor Interacting Protein-1 (RIP1). RIP1 in turn recruits TNF Receptor Associated Factor-2 (TRAF2) and/ or TRAF5, as well as cellular Inhibitor of Apoptosis Protein-1 (CIAP1) and CIAP2 that are TRAF2-associating ubiquitin ligases. These adaptor proteins act in concert with RIP1 to engage downstream phosphorylation cascades to activate NF- $\kappa$ B, JNK, and p38 pathways, which promote proinflammatory and prosurvival transcriptional responses.,

The DRs noted above can be divided into categories based on the primary platform adaptor utilized. For example,

\footnotetext{
${ }^{1}$ Department of Protein Engineering, Genentech Inc., South San Francisco, CA, USA and ${ }^{2}$ Department of Physiological Chemistry, Genentech Inc., South San Francisco, CA, USA

${ }^{*}$ Corresponding author: IE Wertz, Department of Protein Engineering, Genentech Inc., 1 DNA Way, M/S 40, South San Francisco, CA 94080, USA.

Tel: 650 467-6841; Fax: 650 225-6443; E-mail: ingrid@gene.com or dixit@gene.com

Keywords: ubiquitin; death receptor; Fas; TNFR1

Abbreviations: CARD, caspase activation and recruitment domain; DED, death effector domain; DR, death receptor; FADD, Fas-Associated Death Domain; TNFR, tumor necrosis factor receptor; TRADD, TNF Receptor-Associated Death Domain

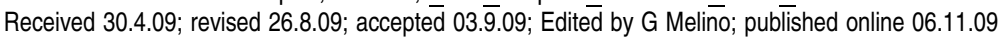


Fas/CD-95, DR4, and DR5 engage FADD and are primarily proapoptotic in function. In contrast, TNFR1, DR3, and possibly DR6 bind TRADD and mediate proinflammatory and proliferative functions. However, there is cross-talk: TNFR1, for example, can under some circumstances promote apoptosis by the TRADD- or RIP1-mediated recruitment of FADD-caspase-8/10. In addition, DR4 and DR5 can activate $\mathrm{NF}-\kappa \mathrm{B}$ through FADD/caspase-8-dependent activation of RIP1. ${ }^{7}$ For brevity and continuity of this review, we will focus our discussion on the signaling pathways downstream of DRs that directly promote apoptosis, which are highlighted in Figure 1. For reference, recent reviews have been written about the ubiquitin-mediated regulation of proinflammatory and prosurvival pathways that are activated downstream of DRs. ${ }^{8,9}$ Furthermore, we will primarily describe pathways initiated by TNFR1 as the prototype of TRADD-mediated DR signaling and Fas-activated pathways as the prototype of FADD-mediated DR signaling. As the Ubiquitin-Proteasome System (UPS) extensively regulates $\bar{D} R$ signaling, we will briefly review the UPS components below.

\section{The Ubiquitin System}

Ubiquitination is the mechanism by which the C-terminus of the 76-amino-acid protein ubiquitin is covalently bound to $\varepsilon$-amino groups of lysine $(\mathrm{K})$ residues, or less commonly to

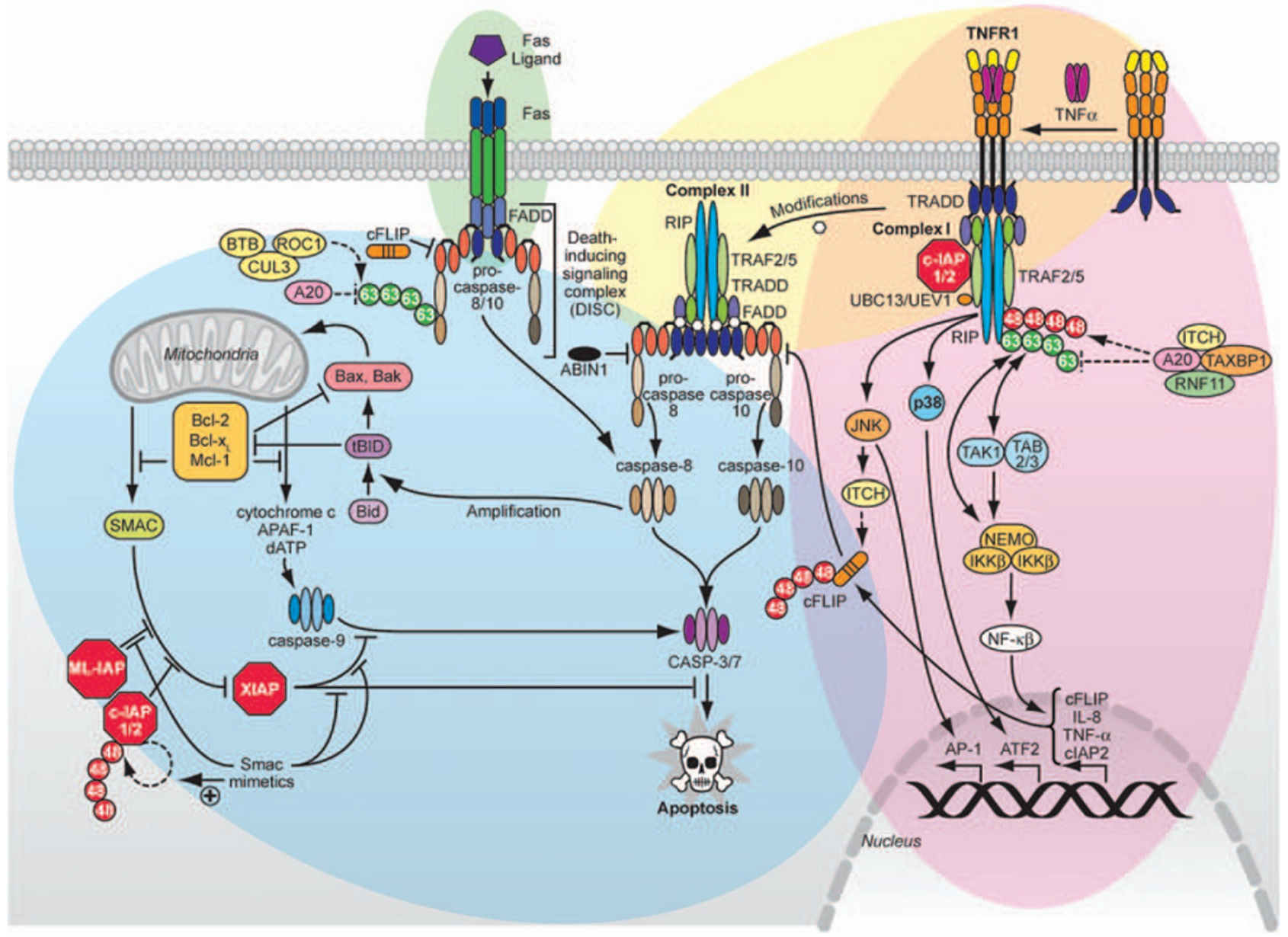

Figure 1 The overlapping and distinct pathways of death receptor signaling. TNF- $\alpha$ binding to TNFR1 promotes the recruitment of the proximal signaling complex (Complex 1) composed of TRADD, TRAF2, and possibly TRAF5, cIAP1/2, and RIP. Prosurvival and proinflammatory pathways downstream of TNFR1 regulate DR-induced apoptosis and are highlighted in pink, and proapoptotic signaling pathways downstream of TNFR1 are highlighted in yellow. cIAP1/2 are E3 ligases that likely catalyze K63linked ubiquitination (green circles) on RIP1, which is critical for activating TNF- $\alpha$-induced signaling. The ubiquitin-editing enzyme A20 de-ubiquitinates K63-linked chains on RIP1 and also promotes K48-linked RIP1 polyubiquitination (red circles) possibly with the aid of ITCH, RNF11, and TAXBP-1. K63 polyubiquitinated RIP1 recruits NEMO of the $I \kappa \mathrm{K}$ complex, thereby stimulating $I_{\kappa} \mathrm{K}$ activity. K63 polyubiquitinated RIP1 may also recruit the TAK/TAB2/3 complex to promote $I_{\kappa} \mathrm{K}$ activation. Activated $I_{\kappa} \mathrm{K}$ phosphorylates $\mathrm{I}-\kappa \mathrm{B}$ leading to its K48-linked ubiquitination and subsequent degradation by the multi-subunit SCF ${ }^{\beta T C P}$ ligase complex. The NF- $\kappa \mathrm{B}$ heterodimer then enters the nucleus to promote transcription of proinflammatory and antiapoptotic genes. TNFR1 also activates p38 and JNK kinases, which activate ATF2 and AP-1 transcription factors, respectively. JNK also activates ITCH to promote K48-linked polyubiquitination of cFLIP, a caspase-8/10 inhibitor. Complex 2 is a proapoptotic signaling complex (highlighted in yellow) that activates caspase-8/10 and downstream effector caspases upon assembly. Activation of Fas promotes recruitment of FADD (highlighted in green), thereby assembling a DISC. Once the apical caspase-8/10 is recruited to FADD, signaling pathways downstream of DRs are common (highlighted in blue). DISC formation may be inhibited by c-FLIP. In type I cells, activation of caspase-8/10 is sufficient to activate the effector caspase-3 and -7 and drive apoptosis. In type II cells, further amplification by caspase-8/10-mediated cleavage of Bid to tBid is required for commitment to apoptosis. tBid stimulates Bax and Bak to promote mitochondrial release of molecules that activate caspase-9. SMAC is also released, which blocks XIAP-mediated caspase inhibition. ML-IAP and CIAP1/2 are believed to bind SMAC and sequester it from XIAP, and SMAC mimetics block ML-IAP, XIAP, and CIAP1/2 and promote Lys48-linked autoubiquitination of cIAP1/2 and their subsequent degradation. See text for additional details 


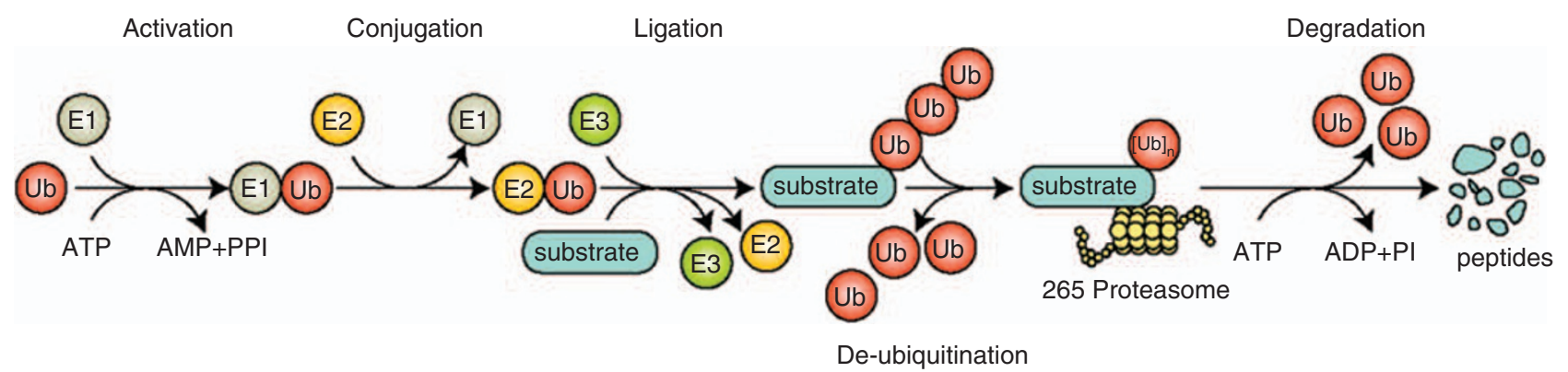

Figure 2 Enzymes and reactions of the ubiquitin/proteasome system. In the activation reaction, the E1 catalyzes the formation of an ubiquitin thiol ester in an ATPdependent reaction. The thiol-linked ubiquitin can then be transferred to an E2 in the conjugation reaction. The ligation reaction is promoted by ubiquitin ligases, or E3 proteins. In this reaction, ubiquitin is covalently bound to the to $\varepsilon$-amino groups of lysine residues, or less commonly to N-termini, of substrate proteins. If polyubiquitin chains are K48linked, the substrate may be targeted to the $26 \mathrm{~S}$ proteasome for degradation. Monoubiquitination and polyubiquitin chains linked by distinct Lys residues may regulate substrates in a nondegradative manner. Ubiquitination may be reversed by de-ubiquitinases (DUBs). See text for additional details

amino termini, of substrate proteins. The process of ubiquitination involves three sequential reactions catalyzed by the E1 (ubiquitin activating), E2 (ubiquitin conjugating/carrier), and E3 (ubiquitin ligase) enzymes of the ubiquitin system ${ }^{10}$ (Figure 2). Polyubiquitin chains can target substrates to the $26 S$ proteasome, and as such, the UPS is the primary conduit for regulated degradation of intracellular proteins. In addition, ubiquitination also regulates a number of cellular processes that do not involve substrate degradation, including cell surface receptor internalization, DNA repair, and protein kinase activation. ${ }^{11}$

Multiple E1, E2, and E3 enzymes have been identified and are highly conserved throughout eukaryotic species, thereby underscoring their fundamentally essential roles. In humans, there are at least two E1 genes, $\sim 50 \mathrm{E2s}$, and upward of 600 E3s, most of which are uncharacterized. ${ }^{12,13}$ As E3 enzymes interact with only a limited number of substrates, they are the primary arbiters of protein ubiquitination. ${ }^{11}$

The E1 first catalyzes the formation of a ubiquitin thiol ester through a ubiquitin adenylate intermediate in an ATPdependent reaction. ${ }^{14}$ The thiol-linked ubiquitin is then transferred to an E2. Depending on what type of E3 the E2 enzyme interacts with, the E2 enzyme may either transfer activated ubiquitin to a catalytic cysteine on an E3 ligase or the E2 may facilitate the ligation of ubiquitin directly to a substrate by an $\mathrm{E} 3^{15}$ (Figure 2).

Both substrates and ubiquitin ligases may be posttranslationally modified. Such modification can either promote or inhibit substrate ubiquitination and ensures that proteins are degraded in the appropriate cellular context. Cellular signaling cascades often induce post-translational modifications of E3 ligases and substrates such as phosphorylation in order to functionally couple substrate ubiquitination with a global cellular stimulus. DR signaling cascades are among the best-studied pathways that promote post-translational modifications of pathway components, which ensure their proper ubiquitin-mediated regulation. Specific examples will be discussed below.

A number of E3 catalytic domains have been identified. All known E3 domains ultimately promote the ligation of activated ubiquitin to the substrate protein; however, the mechanistic details differ. The HECT (Homologous to E6-accessory protein Carboxy Terminus) E3 domain functions as a true ubiquitination catalyst. ${ }^{11,15,16}$ Activated ubiquitin forms a thiol ester with a conserved cysteine within the HECT domain and is then transferred to the substrate protein. ${ }^{17,18}$ Conversely, RING (Really Interesting New Gene) E3 motifs are best considered as molecular scaffolds that facilitate ubiquitin transfer from E2s to substrate proteins, because they do not directly bind ubiquitin. ${ }^{15}$ The A20-type $\mathrm{C}_{2} / \mathrm{C}_{2}$ zinc-finger (ZnF) is the most recently defined E3 ligase motif. ${ }^{19}$ Structural studies of A20-like zinc-finger in Rabex-5 showed that ubiquitin bridges the $\mathrm{ZnF}$ and the E2 catalytic domain, thereby confirming that the A20-like $\mathrm{ZnF}$ is a unique E3 ligase motif. ${ }^{20-22}$

E3 ligases may be composed of multi-subunit complexes or may exist as single proteins. Single protein E3 ligases contain a domain or a motif that promotes ubiquitin ligation to substrates and a distinct substrate-binding site within the same protein. E3 enzyme complexes incorporate RINGcontaining proteins and separate substrate binding subunits that are linked by a variable number of adaptors. This arrangement permits the assembly of enzyme complexes that are both highly specific and precisely regulated. ${ }^{11,23}$ Multi-subunit ligases and single-protein HECT, RING, and A20-type zinc-finger E3 ligases all regulate apoptosis downstream of DR signaling (Figure 1).

The removal of ubiquitin residues from substrates is catalyzed by various De-UBiquitination enzymes (DUBs) (Figures 2, 3). DUBs are cysteine- or metalloproteases that hydrolyze the amide bond after the Gly76 residue of ubiquitin. ${ }^{15}$ There are five subclasses of DUBs: Ubiquitin Carboxy-terminal Hydrolases (UCHs), Ubiquitin- $\underline{\text { Specific }}$ Proteases (USPs), Machado-Joseph Disease protein domain proteases (MJDs), Ovarian TUmor proteases (OTUs), and JAMM motif proteases. ${ }^{24} \overline{\text { USP }}$ and OTU DUBs are key regulators of $\mathrm{DR}$ signaling.

Thus far, we have alluded to ubiquitination of signaling proteins in DR pathways, but it is important to reiterate that the amino terminus or the $\varepsilon$-amino groups of lysine residues on ubiquitin may also serve as substrates for ubiquitination. In this way, polyubiquitin chains are assembled on the target proteins. Ubiquitin has seven lysines, and polyubiquitin chains can be linked through any one of these lysine residues. ${ }^{25}$ Although HECT domain-containing ligases directly determine 
Cellular proteins
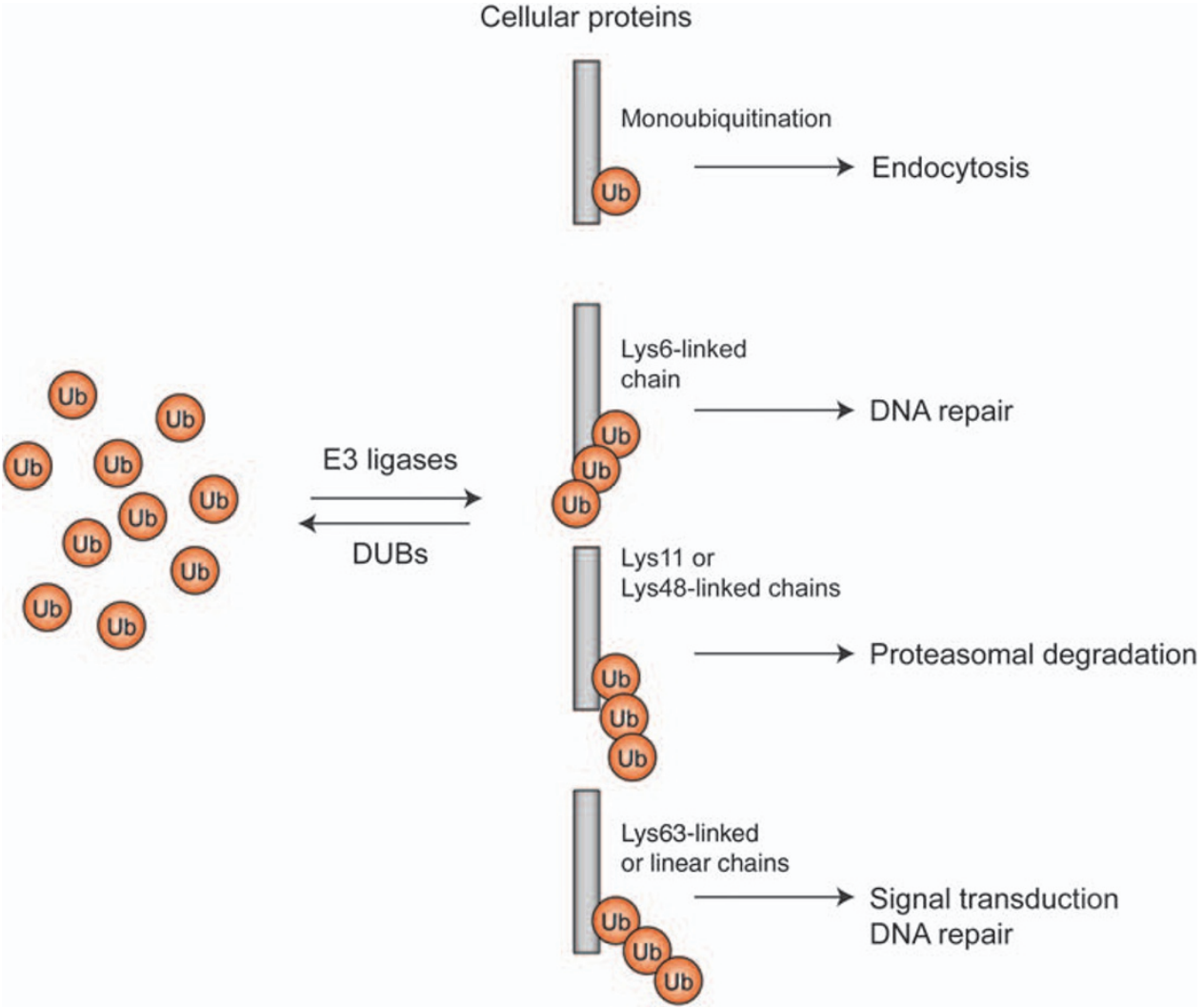

Figure 3 The specific type of ubiquitin modification governs the fate of substrate proteins. Monoubiquitination primarily serves to regulate the internalization of cell-surface proteins and intracellular protein sorting. Lys6-linked polyubiquitin chains has a role in DNA repair. Lys48-linked chains typically target substrates for proteasomal degradation, and K11-linked ubiquitin chains may also promote substrate degradation. Lys63-linked and linear polyubiquitin chains generally do not promote efficient proteasomal degradation, but instead regulate the activation of proinflammatory signaling and other cellular processes. Specialized ubiquitin-binding proteins recognize the specific patterns of ubiquitination on substrate proteins and direct the substrates to the appropriate fate. Thus, it is the characteristic topology of different ubiquitin modifications that confers functional diversity by directing associations with specific sets of proteins. The removal of ubiquitin residues from substrates is catalyzed by various DUBs

the type of linkages that are made within polyubiquitin chains, it is the E2 associated with the RING domain E3s that specifies the nature of polyubiquitin chain linkages. ${ }^{26}$ These specific types of ubiquitin modifications govern the fate of substrate proteins (Figure 3). Polyubiquitin chains linked through $\mathrm{K} 48$ or K63 residues are the best-studied modifications. K48-linked chains typically target substrates for proteasomal degradation, ${ }^{27,28}$ although exceptions are known. ${ }^{29}$ K63-linked polyubiquitin chains generally do not promote efficient proteasomal degradation, but instead regulate the activation of proinflammatory signaling ${ }^{30-34}$ and other cellular processes. ${ }^{35-38}$ Recent evidence suggests that K11-linked ubiquitin chains may promote substrate degradation and that linear ubiquitin chains may also have scaffolding functions. ${ }^{39,40}$ Monoubiquitination is also an important modification and primarily serves to regulate the internalization of cell-surface proteins, intracellular protein sorting, and other cellular activities. ${ }^{41,42}$ Monoubiquitination of several residues on one substrate results in multiple monoubiquitination, which may promote subcellular relocalization ${ }^{43,44}$ or target substrates to the endosome- (as opposed to proteasome-) mediated degradation system. ${ }^{44}$

Specialized ubiquitin-binding proteins recognize the specific patterns of ubiquitination on substrate proteins and direct the substrates to the appropriate fate. In this way, the different ubiquitin arrangements on substrates can promote distinct outcomes. Unlike phosphate or acyl groups, the ubiquitin protein has a complex surface topology. ${ }^{45}$ Thus, it is the characteristic topology of different ubiquitin modifications that confers functional diversity by directing associations with specific sets of proteins. The consequences of substrate ubiquitination in DR signaling cascades will be discussed in more detail below.

\section{DR Signaling is Regulated by Ubiquitination}

\section{TRADD-mediated DR signaling: TNFR1/DR3/DR6}

Mechanisms and components of TRADD signaling pathways. Upon ligand binding, the platform adaptor molecule TRADD promotes the assembly of at least two distinct signaling complexes, which initiate opposing signaling pathways: (1) Complex 1-mediated activation of proinflammatory and antiapoptotic mediators (Figure 1, pink oval), or (2) Complex 2-mediated activation of apoptosis (Figure 1, yellow oval). The gene products ultimately induced by activated Complex 1 regulate cell death pathways downstream of all six DRs, as will be discussed in more 
detail below. However, because the pro-inflammatory and pro-survival signaling pathways emanating from Complex 1 indirectly regulate apoptosis (pink oval, Figure 1), they will only briefly be outlined in this review.

TRADD recruitment to activated DRs organizes the assembly of the remaining Complex 1 proteins: RIP1, cIAP1 and clAP2, TRAF2, and TRAF5. RIP1 is a kinase that is essential for TNF- $\alpha$-mediated NF- $\kappa$ B signaling in a kinaseindependent manner, ${ }^{46,47}$ and is modified by K63-linked polyubiquitination within Complex $1^{5,48}$ The K63-linked polyubiquitin chains assembled on RIP1 function as scaffolds for downstream signaling components including Transforming growth factor- $\beta$ Activated Kinase-1 (TAK1) and its partner protein TAK1 Binding protein-2 (TAB2) that preferentially binds K63-linked polyubiquitin. In addition, NEMO, also by virtue of $\mathrm{K} 63$ polyubiquitin chain binding, recruits the $1 \kappa \mathrm{K}$ complex to Complex 1 . The recruitment and resultant activation of these kinase complexes initiates NF- $\kappa \mathrm{B}$, JNK, and p38 MAPK signaling pathways that ultimately promote proliferative and inflammatory cellular responses. In particular, the heterodimeric NF- $\kappa$ B transcription factor induces the synthesis of proinflammatory cytokines such as TNF- $\alpha$ and IL-8, as well as antiapoptotic factors including C-IAP1/2 and cellular FLICE Inhibitory Protein (c-FLIP) ${ }^{5}$ (Figure 1).

TRADD also facilitates the assembly of one, and perhaps two, distinct cytosolic and proapoptotic complexes that will be highlighted in this review. Micheau and Tschopp ${ }^{49}$ were the first to report that two distinct complexes assemble after TNF$\alpha$ stimulation in order to initiate each opposing branch of the signaling pathways. After Complex 1 is formed, the authors proposed that TRADD and RIP1, due to unknown modifications, dissociate from the remainder of Complex 1 at the membrane and initiate the assembly of Complex 2 in the cytosol. Thus, RIP1, and possibly TRADD, ${ }^{49,50}$ recruits the death adaptor FADD, which has both DD and DED, through DD/ DD interactions. The DED of FADD in turn oligomerize procaspase- 8 and -10 to initiate the apoptotic signaling cascade. ${ }^{51}$

Another group reported that two distinct cytosolic and proapoptotic complexes, Complex $2 \mathrm{~A}$ or $2 \mathrm{~B}$, are formed in response to TNF- $\alpha$ by co-treatment with either the protein synthesis inhibitor cycloheximide (CHX) or IAP antagonists. ${ }^{52}$ Complex $2 \mathrm{~A}$ is formed in response to treatment with TNF- $\alpha$ plus $\mathrm{CHX}$. In this scenario, TRADD dissociates from DRs and binds the DD of FADD, which in turn oligomerizes and activates caspase-8. Complex $2 \mathrm{~B}$ is formed when cells are treated with TNF- $\alpha, \mathrm{CHX}$, and IAP antagonists. The nonubiquitinated form of RIP1 is reported to induce apoptosis by seeding the formation of Complex $2 \mathrm{~B}$. In this complex, the DD of RIP1 binds the FADD DD, which engages caspase-8 to initiate apoptosis. ${ }^{52-54}$

Ubiquitin regulation of TRADD pathway components. Complex 1 is reported to assemble on translocation to membrane lipid rafts, and TNFR1 and RIP1 are ubiquitinated on translocation. ${ }^{55}$ It has also been proposed that ubiquitination within lipid rafts promotes TNFR1 and RIP1 degradation. Disruption of lipid raft formation has been shown to block ubiquitination and subsequent degradation of RIP1 and TNFR1, thereby shunting TNF- $\alpha$-induced signaling from activation of prosurvival signaling pathways to apoptosis. ${ }^{55}$
Thus, at least three different scenarios of RIP1 ubiquitination may dictate whether apoptosis or cell survival predominates in response to TNF- $\alpha$ : (1) ubiquitin-mediated degradation of RIP1, perhaps by K48-linked chains, promotes apoptosis; (2) K63-linked polyubiquitination of RIP1 in Complex 1 facilitates proinflammatory, prosurvival cellular responses by a scaffolding mechanism; and (3) removal of K63-linked ubiquitin chains from RIP1 promotes the assembly of Complex $2 \mathrm{~B}$ and activates apoptosis. An unsolved mystery in the field of TNFR1 biology is to determine what dictates whether the prosurvival/proinflammatory pathways or the proapoptotic pathways will predominate in response to TNF- $\alpha$. The ubiquitination status of RIP1, and perhaps of other signaling components, may be the key regulators of cell fate.

A number of proteins that harbor ubiquitin ligase domains are recruited to Complex 1 and are therefore contenders for promoting RIP1 ubiquitination. TRAF2 is a RING domain E3 that is essential for TNF- $\alpha$-stimulated JNK and NF- $\kappa$ B signaling, ${ }^{56,57}$ possibly in collaboration with the heterodimeric E2 UBC13/UEV1. ${ }^{32}$ TRAF2 is reported to promote K63-linked polyubiquitination of RIP1 but not of itself. ${ }^{58}$ Evidence for TRAF2-mediated RIP1 ubiquitination is based on TRAF2 $\mathrm{RNAi}^{19}$ and gene ablation ${ }^{59}$ experiments, which showed decreased RIP1 ubiquitination in the absence of TRAF2. However, formal proof showing direct ubiquitination of RIP1 by TRAF2 is still needed. TRAF5 is another RING domain protein that may also have E3 ligase activity, given that alignments of the TRAF2 and TRAF5 RING domains show potential functional similarities, ${ }^{60}$ and both the TRAF2 ${ }^{61}$ and the TRAF5 ${ }^{62}$ RING domains are required to activate downstream signaling events. Furthermore, TRAF2 and TRAF5 are functionally redundant in attenuating TNF- $\alpha$-induced apoptosis and promoting NF- $\kappa$ B activation. ${ }^{57}$ However, formal proof of TRAF5 E3 ligase activity is missing, and targets of TRAF5 ubiquitination have not yet been identified.

The clAP1/2 proteins are RING E3s that were initially identified in association with TNFR2. ${ }^{63}$ Subsequent studies showed that CIAP1 and clAP2 are also recruited to activated TNFR1 through TRAF2. ${ }^{48,64}$ clAP1/2 proteins are transcriptionally upregulated by TNF- $\alpha$ and cooperate with TRAFs to inhibit TNF- $\alpha$-induced apoptosis. ${ }^{65}$ Although ClAP1- ${ }^{66}$ and ClAP2- ${ }^{67}$ deficient mice had no obvious deficit in TNF- $\alpha-$ induced signaling pathways, ablation of both clAP1 and clAP2 showed their essential roles in NF- $\kappa$ B activation downstream of TNFR1 ${ }^{54,68,69}$ Furthermore, clAP1 and clAP2 were shown to promote RIP1 polyubiquitination in vivo, which was shown to be K63-linked in vitro. Thus, it is likely that clAP1 and clAP2 promote TNF- $\alpha$-induced NF- $\kappa$ B activation and block apoptosis by K63-linked ubiquitination of RIP1. Given these findings, it is unclear what the specific roles are of TRAF2, TRAF5, and clAP1, and clAP2 in RIP1 ubiquitination and NF- $\kappa$ B activation. On one extreme, it is possible that TRAF2 and TRAF5 simply serve to recruit ClAP1 and ClAP2 to TNFR1 and have no additional role in RIP1 ubiquitination. Other possibilities are that the RING domains of CIAP1/2 regulate TRAF2 and TRAF5 ubiquitin ligase activity, or vice versa, or that TRAF2 and TRAF5 and ClAP1/2 ubiquitinate RIP1 on different sites and/or in different contexts to fine-tune TNFR1 NF- $\kappa$ B activation and apoptosis. 
The importance of the E2 UBC13 in TNF- $\alpha$-mediated signaling was first shown by expression of a dominantnegative version of UBC13 (C87A) that blocked TNF- $\alpha$ - and TRAF2-induced NF- $\kappa$ B activity. ${ }^{30}$ UBC13 RNAi was also reported to block TNF- $\alpha$-induced JNK activation, further implicating its cooperation with TRAF2. ${ }^{70}$ However, UBC13 genetic ablation experiments have generated conflicting findings. As homozygous UBC13 ablation was embryonic lethal, either hemizygous $\mathrm{UBC} 13^{-1+}$ mice $^{71}$ or mice conditionally deficient in $\mathrm{UBC} 13^{72,73}$ were analyzed. In response to TNF- $\alpha, \mathrm{UBC} 13^{+/-}$macrophages and splenocytes showed blunted activation of NF- $\kappa \mathrm{B}$, JNK, and p38 signaling pathways. ${ }^{71}$ In contrast, UBC13 $3^{-1-}$ MEFs displayed no alteration in these signaling pathways relative to wild-type MEFs. ${ }^{72}$ Although these discrepancies may be attributable to cell type-specific differences, experiments with UBC13 null cells suggest that other E2 enzymes may substitute for UBC13 in TNF- $\alpha$ signaling pathways. This idea was also implied by earlier studies using UBC4/5 to activate the $1 \kappa \mathrm{K}$ complex. ${ }^{74}$ In corroboration with these findings, Varfolomeev et al. ${ }^{68}$ reported that clAP1 cooperates with hUBC5A, but not hUBC13/UEV1, to polyubiquitinate RIP1 with K63-linked chains in vitro.
The ubiquitin-editing enzyme A20 is proposed to regulate RIP1 ubiquitination both as an E3 ligase and as a DUB (Figure 4). A20 was identified in $1990^{75,76}$ and genetic ablation experiments established $\mathrm{A} 20$ as a critical negative regulator of TNF- $\alpha$-induced NF- $\kappa$ B signaling 10 years later. ${ }^{77}$ A20 contains both an OTU DUB domain and $\mathrm{C}_{2} / \mathrm{C}_{2} \mathrm{ZnF}$ E3 ligase motif and attenuates NF- $\kappa \mathrm{B}$ signaling in a two-step process: the A20 DUB domain first removes K63-linked ubiquitin chains from RIP1, and the A20 E3 ligase domain then promotes ligation of K48-linked ubiquitin chains to RIP1. As K63ubiquitinated RIP1 is required for $N F-\kappa B$ signaling, A20-mediated RIP1 de-ubiquitination and subsequent proteasomal degradation cooperate to downregulate NF- $\kappa \mathrm{B}$ signaling. ${ }^{19}$

Several modulators of A20 ubiquitin ligase activity have also been identified. TAXBP1, a Binding Protein of the hTLV TAX protein, was identified as an A20-binding protein in a yeast two-hybrid screen and was reported to cooperate with A20 to attenuate TNF- $\alpha$ signaling. ${ }^{78}$ TAXBP1-deficient MEFs confirmed these initial findings, revealing enhanced TNF- $\alpha$ induced $\mathrm{I} \kappa \mathrm{K}$ and JNK activation and increased RIP1 ubiquitination. These effects were believed to result from decreased association of RIP1 with A20 in the absence of TAXBP1. ${ }^{79,80}$
clAP1
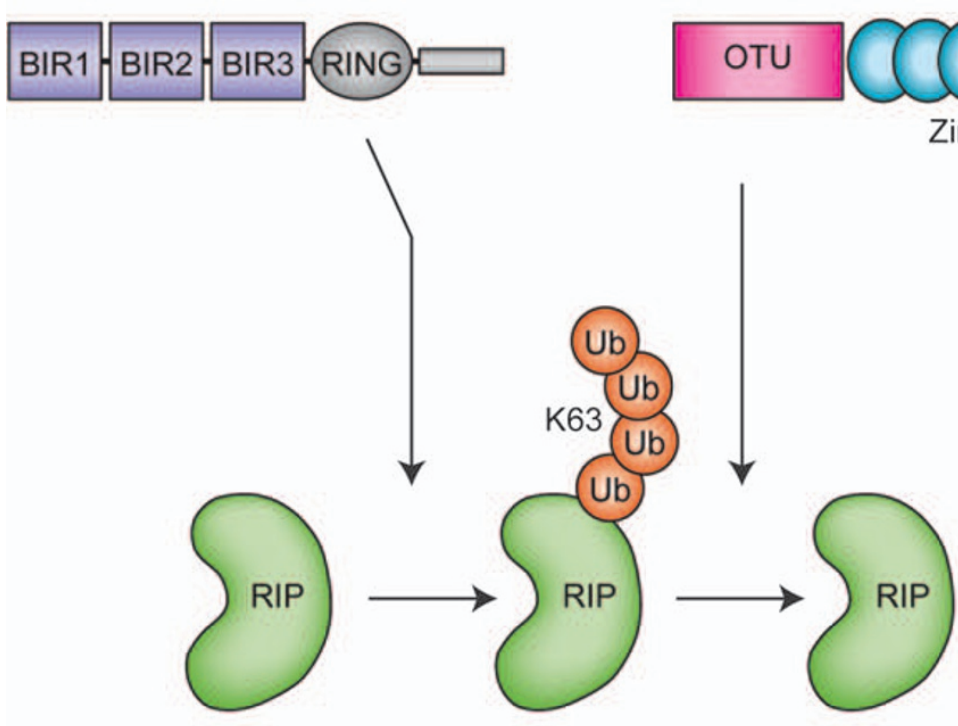

A20

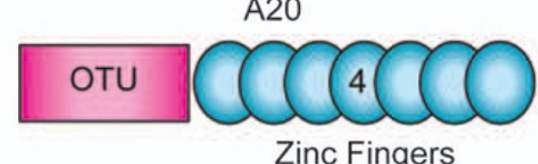

Zinc Fingers
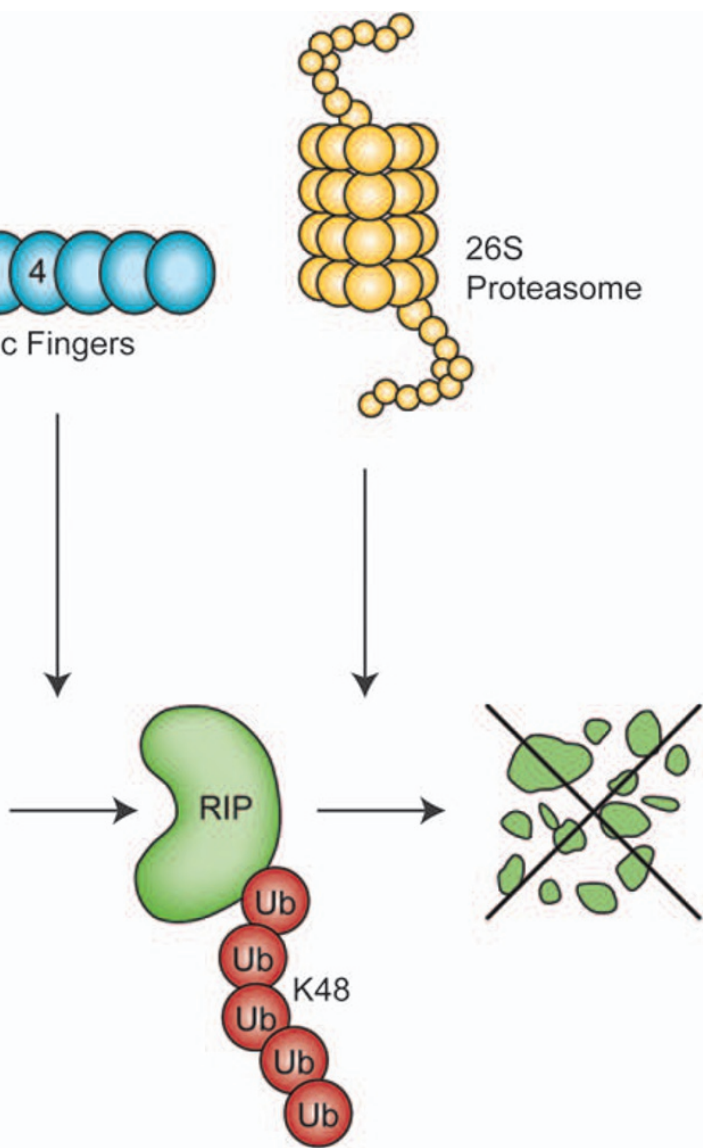

Figure 4 Ubiquitin editing is mediated by a complex interplay between the ubiquitination and deubiquitination machinery within the proximal receptor-associated signaling complex, resulting in the replacement of signal-enhancing lysine 63-linked polyubiquitin with signal extinguishing lysine 48-linked polyubiquitin. More specifically, the ubiquitinediting enzyme $A 20$ is proposed to regulate RIP1 ubiquitination both as an E3 ligase and as a DUB. A20 contains both an OTU DUB domain and a $C_{2} / C_{2} Z n F E 3$ ligase domain and attenuates NF- $\kappa$ B signaling in a two-step process: the A20 DUB domain first removes K63-linked ubiquitin chains from RIP1, and the A20 E3 ligase domain then promotes ligation of K48-linked ubiquitin chains to RIP1. As K63 ubiquitinated RIP1 is required for NF- $\kappa$ B signaling, A20-mediated RIP1 de-ubiquitination and subsequent proteasomal degradation downregulates NF- $\kappa$ B signaling 
As the HECT-domain ubiquitin ligase Itch also binds A20 through TAXBP1, it was proposed that Itch facilitates A20-mediated RIP1 ubiquitination, degradation, and resultant downregulation of TNF- $\alpha$-mediated signaling. ${ }^{81}$ The RING domain E3 RNF11 was also reported to participate in the ubiquitin-mediated degradation of RIP1 after TNF- $\alpha$ treatment in collaboration with TAXBP1 and Itch. ${ }^{82}$ The precise roles for each $\mathrm{E} 3$ recruited to the $\mathrm{A} 20$ ubiquitin-editing enzyme will be interesting to decipher.

A number of additional RIP1 DUBs have also been reported. Similar to A20, the A20-like protein Cellular Zinc finger ANti-NF- $\kappa \mathrm{B}$ (Cezanne) also has an OTU domain. ${ }^{83}$ Evidence suggests that on TNF- $\alpha$ stimulation, Cezanne is recruited to TNFR1 and promotes RIP1 de-ubiquitination, thereby attenuating NF- $\kappa$ B signaling. ${ }^{84}$ The tumor suppressor CYLD is also a proposed RIP1 de-ubiquitinating enzyme. ${ }^{52,85}$ The association of CYLD with TNFR1 signaling was first made when CYLD was shown to disassemble K63-linked chains from NEMO and TRAF proteins to attenuate downstream signaling cascades. ${ }^{33,86,87}$ These data have been supported by studies in CYLD $^{-1-}$ cells and animals, ${ }^{88,89}$ and similar mechanisms appear to be conserved in Drosophila. ${ }^{90} \mathrm{How}$ ever, the role of CYLD in TNF- $\alpha$-induced RIP1 de-ubiquitination is less clear. There were no differences in RIP1 ubiquitination between $\mathrm{CYLD}^{+/+}$and $\mathrm{CYLD}^{-1-}$ peritoneal macrophages after TNF- $\alpha$ treatment, ${ }^{88}$ whereas in CYLD ${ }^{-1-}$ testicular germ cells, TNF- $\alpha$-induced RIP1 ubiquitination was persistent. ${ }^{85}$ On the basis of RNAi ablation studies, CYLD was also proposed to de-ubiquitinate RIP1 and thereby promote activation of the apoptosis-inducing Complex 2B in Panc-1 cells. ${ }^{52}$ Given the apparent cell type and context-dependent nature of CYLD substrates, it will be important to confirm whether CYLD affects the RIP1 ubiquitination status in Complex $2 \mathrm{~A}$ in these and other cell lines.

Although TRADD initiates DR signaling as a platform for the assembly of signaling components and ubiquitin-modifying enzymes, it is preferable to discuss the role of TRADD in TNFR1 signaling after the mechanisms of downstream proteins have been reviewed in order to best appreciate the central role that TRADD has in DR signaling. TRADD was discovered in $1995^{91}$ but definitive genetic evidence of the role of TRADD in TNFR1-mediated apoptosis was only recently reported. $^{92,93}$ TRADD deficiency blocked TNFR1-induced cell death induced by TNF $+\mathrm{CHX}$ in vitro and by TNF + GaIN in vivo, thereby establishing the essential role of TRADD in proapoptotic signaling downstream of DRs. These studies also analyzed the components of Complex 1 recruited to TNFR1 and found that in the absence of TRADD, less RIP1 and no TRAF2 were associated, and that ubiquitination of RIP1 was markedly reduced. The authors concluded that activation of proinflammatory, prosurvival pathways was attenuated due to ineffective modification of RIP1 by K63linked polyubiquitin chains. However, it can be noted that neither group evaluated the levels of clAP1/2 in Complex 1 nor was the association of FADD with RIP1 or caspase-8 compared in the absence or presence of TRADD. Collectively, the data suggest that TRADD has an important role in the TNFR1-induced cell death observed in some cellular contexts. The exact mechanisms by which such TRADD ablation affects apoptosis are not fully understood, but may include ineffective oligomerization of FADD and caspase-8, decreased pro-survival signals emanating from Complex 1 that favor induction of cell death, or a combination of both scenarios.

\section{FADD-mediated DR signaling: Fas/DR4/DR5}

Components and mechanisms unique to FADD signaling pathways. As depicted in Figure 1 (green oval), the signaling steps that are unique to FADD-mediated DR signaling are limited, because the TRADD-mediated DR signaling pathways feed in at a proximal step. Thus, ligand/DR binding, recruitment of FADD to Fas, DR4, or DR5 by DD/ DD interactions, and recruitment of caspase-8/10 to the Death-Inducing Signaling Complex (DISC) are the only signaling steps that are unique. Nevertheless, the ubiquitin system still exerts regulation on these proximal steps.

Ubiquitin regulation of FADD pathway components. In the case of Fas, ubiquitin-mediated regulation signaling begins upstream of the receptor. Fas ligand may bind Fas in a membrane-bound form or in a cleaved soluble form, but the membrane-bound form is estimated to be $\sim 1000$ times more biologically active. Studies have shown that the membranebound form of Fas ligand is targeted to the multivesicular bodies of secretory lysosomes and is subsequently released by exosome-like vesicles into the immunological synaptic cleft. Phosphorylation and monoubiquitination independently regulate the sorting of Fas ligand to secretory lysosomes by promoting their entry into multivesicular bodies, thereby providing the most potently active form of membrane-bound Fas ligand available to trigger rapid cell death. ${ }^{94}$

\section{Pathways common to DR signaling}

Components and mechanisms common to DR signaling pathways. DR signaling pathways that use TRADD as the proximal DD adaptor feed into a common pathway shared by DRs at the point of FADD oligomerization and subsequent activation of caspase-8/10 (Figure 1, yellow and blue ovals). Upon dissociation from DRs such as TNFR1, DR3, and possibly DR6, the DDs of TRADD and/or RIP1 are free to associate with FADD. FADD-mediated oligomerization of the zymogen forms of caspase- 8 and -10 triggers their activation through an induced proximity change in conformation. Thus, after FADD-mediated oligomerization of caspase-8/10, the downstream signaling pathways of the various DRs are shared (Figure 1, blue oval).

The complex of DR/FADD/caspase-8/10 is referred to as the DISC. However, the DD of TRADD and/or RIP1 form the functional equivalent of a FADD-associated DR by recruiting FADD and caspase-8/10. Thus, the complexes containing FADD and caspase-8/10 assembled by DRs, RIP1, or TRADD can all be considered as DISCs. A critical regulator of the DISC that determines the degree of activation of the apical caspases is the decoy molecule cFLIP-Long (c-FLIP $P_{L}$ ). c-FLIP $P_{L}$ possesses substantial sequence identity to caspase-8/10 except that it lacks the cysteine residue essential for catalytic activity. C-FLIP $\mathrm{P}_{\mathrm{L}}$ effectively inhibits activation of caspase- $8 / 10$ by binding FADD and displacing caspase- $8 / 10 .^{95}$

Activated caspase-8/10 function to amplify the 'death signal' by proteolytically activating downstream effector caspases including caspase- $3,-6$, and -7 resulting in the 
cleavage of death substrates and subsequent rapid demise of the cell. ${ }^{4}$ However, for this proteolytic cascade to propagate, the activity of the apical caspases, caspase-8/10 and caspase9, must exceed a threshold value. Indeed, cells may be classified based on the mechanism by which effector caspases are activated. In type I cells, such as lymphocytes, caspase-8/ 10 directly activate downstream effector caspases (Figure 1). In contrast, type II cells such as hepatocytes and pancreatic $\beta$-cells may induce apoptosis by engaging the intrinsic or mitochondrial death pathway. This involves the caspase-8/10mediated cleavage of the $\mathrm{Bcl}-2$ family protein Bid to create a proapoptotic molecule, termed t-Bid. t-Bid ultimately activates Bax and Bak to induce mitochondrial membrane permeabilization, release of mitochondrial factors such as cytochrome $c$ that induce proteolytically competent caspase-9, and activation of downstream effector caspases (Figure 1). ${ }^{4}$ Another factor released from permeabilized mitochondria that accelerates the apoptotic cascade is SMAC/DIABLO, a neutralizer of IAPS. IAPs functionally inhibit caspases, ${ }^{96}$ and it is believed that the levels of XIAP determine whether cells execute type I or type II apoptotic pathways. ${ }^{97}$

Ubiquitin regulation of common DR signaling pathways. Just like the ubiquitination status of RIP1 is a checkpoint that has a critical role in determining cell fate in response to TNF- $\alpha$, the DD-mediated assembly of the FADD and caspase-8/10 is another crucial point of regulation for the initiation of apoptosis. Thus, several mechanisms are used by cells to carefully monitor the assembly of this complex. For example, regulation of $C F L I P_{L}$ is a critical determinant of cell fate in response to $\mathrm{TNF}-\alpha$. Whereas $\mathrm{NF}-\kappa \mathrm{B}$ transcriptionally upregulates $C F L I P L$ to inhibit caspase-8-mediated apoptosis, the HECT domain ubiquitin ligase Itch promotes c-FLIP $\mathrm{L}_{\mathrm{L}}$ degradation to activate apoptosis. ${ }^{98}$ Itch is activated by JNK1 phosphorylation, ${ }^{99}$ thus JNK functionally promotes cFLIP $_{\mathrm{L}}$ turnover by Itch activation ${ }^{100}$ (Figure 1).

A20 Binding and Inhibitor of NF- $\kappa$ B-1 (ABIN1) also regulates caspase-8 recruitment to $\bar{F}$ - $A D D$. ABIN proteins were originally identified as three distinct NF- $\kappa \mathrm{B}$ inhibitory proteins that bind $\mathrm{A} 20$, but their respective mechanisms of action have been elusive. The first hints were the identification of a novel Ubiquitin Binding Domain (UBD) in ABIN proteins termed UBAN (UBD in ABIN proteins and NEMO). ${ }^{101}$ Genetic ablation of $A B \overline{I N 1}$ showed that $A B I N 1-\overline{d e f i c i e n t}$ cells were hypersensitive to TNF- $\alpha$-induced cell death, and that ABIN1 blocked caspase-8 recruitment to FADD. Interestingly, ABIN1 did not require the presence of $A 20$ to regulate apoptosis, and the ubiquitin-binding domain of $A B I N 1$ is required for its antiapoptotic function. Furthermore, the ubiquitin-binding activity of ABIN1 is required for association with FADD and RIP1 and also for ABIN1-mediated inhibition of FADD/ caspase-8 binding. ${ }^{102}$ Thus, it is possible that association of ABIN1 with ubiquitinated RIP1 somehow inhibits the FADD/ caspase-8 interaction. The function of ABIN1-deficient cells was evaluated in the context of TNF- $\alpha$-mediated signaling pathways, thus it would also be interesting to determine whether ABIN1 inhibits Fas-induced FADD/caspase-8 binding. If so, this would suggest that $A B I N 1$ associates with ubiquitinated proteins that are common to TRADD- and FADD-mediated apoptotic pathways - perhaps FADD and/or caspase-8.
There is indeed evidence that caspase- 8 is modified by K63-linked chains. Jin et al. ${ }^{103}$ recently reported that DR4/5 stimulation by Apo2L/TRAIL induces K63-linked ubiquitination of caspase-8. Caspase- 8 is polyubiquitinated on the $p 10$ subunit, which stabilizes the processed caspase- 8 heterotetramer by recruiting the ubiquitin-binding protein p62. K63polyubiquitinated caspase- 8 has more potent enzymatic activity and more readily promotes apoptosis, and RNAi of CUL3, ROC1, and p62 attenuate Apo2L/TRAIL-induced apoptosis. ${ }^{103}$ The report of K63-linked ubiquitin chain polymerization by a cullin-containing ubiquitin ligase complex is novel. As caspase-8 is modified by both K48- and K63-linked polyubiquitin chains after Apo2L treatment, ${ }^{103}$ it will be interesting to identify the physiological E2 used by the CUL3 ligase complex and to determine how the E2 binds ROC1 and orients the acceptor ubiquitin such that K63-linked ubiquitin chains are polymerized. A20 is recruited to the complex and mediates caspase- 8 deubiquitination, ${ }^{103}$ thus it is also possible that $\mathrm{A} 20$ facilitates caspase-8 K48 polyubiquitination. In addition, the identity of the adaptor protein that recruits caspase-8 to the CUL3/ROC1 complex is of intense interest. Finally, it will be important to determine the specific DR signaling pathways in which polyubiquitinated caspase- 8 and ABIN1 function.

IAP family members can also regulate caspase activity, and thereby attenuate apoptosis. As discussed above clAP1 and clAP2 function at proximal TNFR1 signaling complexes, and additional IAP family members function in distal pathways that are common to all DRs by inhibiting caspase activity. However, the precise mechanisms by which IAPs achieve this critical function have remained a mystery since their initial discovery over 15 years ago. ${ }^{104}$ This enigma may in part be due to the fundamental differences between the functions of IAPs within the two primary systems in which these proteins are studied: mammals and Drosophila. For example, the E3 ligase activity of Drosophila IAP1 (dIAP1) is required to block apoptosis, likely by promoting ubiquitination of the Drosophila caspases drICE, DRONC, and DCP-1. Recent evidence suggests that dIAP1-mediated polyubiquitination of drICE effectively blocks caspase activity in a degradation-independent manner. Furthermore, dIAP1 is cleaved by caspases, which exposes a binding site on dIAP1 for UBR-containing ubiquitin ligases. ${ }^{105}$ These UBR ligases then act in concert with dIAP1 to block caspase activity in vivo. ${ }^{106}$ Other targets of Drosophila IAP E3 ligase activity may be endogenous IAP antagonists such as HID, Grim, and Reaper. ${ }^{107}$

However, in mammalian systems, definitive evidence for ubiquitin-mediated caspase inhibition by IAPs in vivo is lacking. ${ }^{107}$ Instead, structural and functional studies indicate that XIAP blocks DR-induced apoptosis by directly inhibiting the activity of caspase- $9,-7$, and -3 in a ubiquitin-independent manner, and ML-IAP is reported to block the activity of SMAC/ Diablo. ${ }^{108}$ It is proposed that the key mechanisms of IAP antagonist-induced apoptosis are to block the inhibition of XIAP and ML-IAP on their respective substrates, thereby releasing the brakes on apoptosis and allowing cell death to proceed. The functional consequence of IAP-mediated ubiquitination and degradation of endogenous IAP antagonists such as SMAC/Diablo or HtrA2/Omi in mammalian systems is unclear. ${ }^{107}$ 
The recent identification of UBA domains within IAPs by two groups shows another mechanism of ubiquitin-mediated regulation by these complex proteins. Both groups reported that the UBA domain regulates cell survival by binding to ubiquitin and that the UBA in CIAP1 is not required for its E3 ligase activity or autoubiquitination. However, the studies show conflicting data regarding what forms of ubiquitin the UBA domains bind and what the additional effects of mutating the UBA domain are. Gyrd-Hansen et al. tested ubiquitin binding to clAP1/2, XIAP, and dIAP2 and found that no IAPs bound mono-Ub, whereas all IAPs bound K63-linked chains, and ClAP1 and dIAP2 also bound K48-linked chains. This group also reported that the UBA domain is essential for promoting cell survival and activating NF- $\kappa$ B signaling downstream of TNFR1. They further proposed that the UBA domain of the clAP2/MALT1 fusion mediates constitutive activation of NF- $\kappa \mathrm{B}$ by interacting with polyubiquitinated NEMO. ${ }^{109}$ In contrast, Blankenship et al. found that clAP1 bound mono-, K48-linked, and K63-linked ubiquitin. Mutating the UBA domains also attenuated the antiapoptotic activity of clAP1/ 2 , but they ruled out a role for UBAs for modulating clAPmediated NF- $\kappa$ B activation because mutations in the ubiquitin-binding region failed to impair clAP-mediated $\mathrm{NF}-\kappa \mathrm{B}$ activation. Furthermore, they reported that the UBA domain is not required for recruitment to the proximal TNF- $\alpha$ receptor complex or for binding to TRAF2 and Smac, and that wild-type and UBA-mutant clAP2/MALT1 fusion stimulated NF- $\kappa$ B activity and promoted NEMO ubiquitination equally well. Blankenship et al. ${ }^{110}$ also found that proteasomal degradation of clAP1/2 induced by IAP antagonists was attenuated in UBA mutants, suggesting a role of the UBA in proteasome targeting. Despite the discrepancies, both studies suggest that the UBA domain is an important regulator of IAP function and open additional areas of study pertaining to the ubiquitinmediated regulation of DR signaling by IAPS.

$\mathrm{Bcl} 2$ family members are also regulated by ubiquitination downstream of DR signaling. In type 2 cells, the apoptotic cascade must be amplified for induction of cell death, and this is achieved by caspase-8-mediated cleavage and subsequent activation of the proapoptotic $\mathrm{Bcl} 2$ family member Bid (Figure 1). The cleaved form, tBid, then promotes the disruption of mitochondrial membrane integrity by two other proapoptotic Bcl2 family members, Bax and Bak, to accelerate cell death. Both Bid and Bax are reported to be regulated by ubiquitin-mediated degradation. The ubiquitination sites on tBid were mapped and when mutated, conferred tBid stabilization and promoted apoptosis. ${ }^{111}$ Although the cytosolic form of Bax appears to be stable, the activated mitochondrial form is reported to be unstable. Enhanced degradation of mitochondrial Bax is reported in prostate cancers $^{112}$ and in malignant $B$ cells, and the therapeutic proteasome inhibitor Velcade has been shown to stabilize Bax and sensitize CLL cells to TRAIL-induced apoptosis. ${ }^{113}$ The ubiquitination site of Bax has been mapped to the alpha- 5 helix, that when deleted, stabilized Bax protein levels. ${ }^{114}$ Furthermore, it is believed that there may be two Bax isoforms. Although Bax- $\alpha$ is the latent cytosolic form that is activated by the induction of apoptosis, $\operatorname{Bax}-\beta$ may be able to spontaneously integrate into mitochondrial membranes and induce cytochrome $c$ release and is tightly regulated by the
UPS. Upon activation of apoptosis, UPS-mediated degradation of $\mathrm{Bax}-\beta$ is attenuated, thus $\mathrm{Bax}-\beta$ accumulates and disrupts mitochondrial membranes to accelerate apoptosis. ${ }^{115}$

\section{Conclusions}

The importance of ubiquitination in DR signaling is evident from gene deletion studies and biochemical observations. Indeed, the field is faced with an 'embarrassment of riches' for example, multiple ubiquitin ligases are reported to mediate the same ubiquitin modification on identical substrates, such as K63-linked ubiquitination of RIP1. Furthermore, there is likely cross-talk between each of these ubiquitin ligases and substrates. Given these complex networks of protein interactions, how can researchers obtain clarity? We will need more powerful tools that, fortunately, are possible to engineer. For example, the generation of ubiquitin linkage-specific antibodies can temporally monitor the modification of endogenous signaling components and will provide a wealth of information by allowing one to evaluate specific ubiqutin modifications of signaling components in wild-type and genedeleted cells and mice. In this regard, it will be critical to generate knock-in mice harboring point mutations of critical catalytic residues within various DUBs and ligases. These tools will allow one to specifically define the role of the ubiquitin-regulatory activity of such proteins without disrupting their normal scaffolding function.

\section{Conflict of interest}

The authors declare no conflict of interest.

Acknowledgements. We thank Domagoj Vucic, Eugene Varfolomeev, and Wayne Fairbrother for insightful discussions and Allison Bruce for graphics assistance. Our apologies to our colleagues whose important contributions are not cited due to space constraints.

1. Locksley RM, Killeen N, Lenardo MJ. The TNF and TNF receptor superfamilies: integrating mammalian biology. Cell 2001; 104: 487-501.

2. Ashkenazi A, Dixit VM. Death receptors: signaling and modulation. Science 1998; 281: 1305-1308.

3. Fesik SW. Insights into programmed cell death through structural biology. Cell 2000; 103: 273-282.

4. Peter ME, Krammer PH. The CD95(APO-1/Fas) DISC and beyond. Cell Death Differ 2003; 10: 26-35.

5. Hayden MS, Ghosh S. Shared principles in NF-kappaB signaling. Cell 2008; 132: 344-362.

6. Varfolomeev E, Vucic D. (Un)expected roles of C-IAPs in apoptotic and NFkappaB signaling pathways. Cell Cycle 2008; 7: 1511-1521.

7. Wilson NS, Dixit V, Ashkenazi A. Death receptor signal transducers: nodes of coordination in immune signaling networks. Nat Immunol 2009; 10: 348-355.

8. Wertz IE, Dixit VM. Ubiquitin-mediated regulation of TNFR1 signaling. Cytokine Growth Factor Rev 2008; 19: 313-324.

9. Chen ZJ. Ubiquitin signalling in the NF-kappaB pathway. Nat Cell Biol 2005; 7: 758-765

10. Hershko A, Ciechanover A. The ubiquitin system. Annu Rev Biochem 1998; 67: 425-479.

11. Jackson PK, Eldridge AG, Freed E, Furstenthal L, Hsu JY, Kaiser BK et al. The lore of the RINGs: substrate recognition and catalysis by ubiquitin ligases. Trends Cell Biol 2000; 10: 429-439.

12. Pickart CM. Back to the future with ubiquitin. Cell 2004; 116: 181-190.

13. Jin J, Li X, Gygi SP, Harper JW. Dual E1 activation systems for ubiquitin differentially regulate E2 enzyme charging. Nature 2007; 447: 1135-1138.

14. Haas AL, Warms JV, Hershko A, Rose IA. Ubiquitin-activating enzyme. Mechanism and role in protein-ubiquitin conjugation. J Biol Chem 1982; 257: 2543-2548.

15. Glickman $\mathrm{MH}$, Ciechanover $A$. The ubiquitin-proteasome proteolytic pathway: destruction for the sake of construction. Physiol Rev 2002; 82: 373-428.

16. Pickart CM. Mechanisms underlying ubiquitination. Annu Rev Biochem 2001; 70: 503-533. 
17. Huibregtse JM, Scheffner M, Beaudenon S, Howley PM. A family of proteins structurally and functionally related to the E6-AP ubiquitin-protein ligase. Proc Natl Acad Sci USA 1995; 92: 2563-2567.

18. Scheffner M, Nuber U, Huibregtse JM. Protein ubiquitination involving an E1-E2-E3 enzyme ubiquitin thioester cascade. Nature 1995; 373: 81-83.

19. Wertz IE, O'Rourke KM, Zhou H, Eby M, Aravind L, Seshagiri S et al. De-ubiquitination and ubiquitin ligase domains of A20 downregulate NF-kappaB signalling. Nature 2004; 430: 694-699.

20. Lee S, Tsai YC, Mattera R, Smith WJ, Kostelansky MS, Weissman AM et al. Structural basis for ubiquitin recognition and autoubiquitination by Rabex-5. Nat Struct Mol Biol 2006; 13: 264-271.

21. Penengo L, Mapelli M, Murachelli AG, Confalonieri S, Magri L, Musacchio A et al. Crystal structure of the ubiquitin binding domains of rabex- 5 reveals two modes of interaction with ubiquitin. Cell 2006; 124: 1183-1195.

22. Mattera R, Tsai YC, Weissman AM, Bonifacino JS. The Rab5 guanine nucleotide exchange factor Rabex-5 binds ubiquitin (Ub) and functions as a Ub ligase through an atypical Ub-interacting motif and a zinc finger domain. J Biol Chem 2006 281: 6874-6883.

23. van den Heuvel S. Protein degradation: CUL-3 and BTB - partners in proteolysis. Curr Biol 2004; 14: R59-R61.

24. Nijman SM, Luna-Vargas MP, Velds A, Brummelkamp TR, Dirac AM, Sixma TK et al. A genomic and functional inventory of deubiquitinating enzymes. Cell 2005; 123: 773-786.

25. Peng J, Schwartz D, Elias JE, Thoreen CC, Cheng D, Marsischky G et al. A proteomics approach to understanding protein ubiquitination. Nat Biotechnol 2003; 21: 921-926.

26. Deshaies RJ, Joazeiro CA. RING domain E3 ubiquitin ligases. Annu Rev Biochem 2009; 78: 399-434.

27. Chau V, Tobias JW, Bachmair A, Marriott D, Ecker DJ, Gonda DK et al. A multiubiquitin chain is confined to specific lysine in a targeted short-lived protein. Science 1989; 243 : 1576-1583.

28. Finley D, Sadis S, Monia BP, Boucher P, Ecker DJ, Crooke ST et al. Inhibition of proteolysis and cell cycle progression in a multiubiquitination-deficient yeast mutant. Mol Cell Biol 1994; 14: 5501-5509.

29. Flick K, Ouni I, Wohlschlegel JA, Capati C, McDonald WH, Yates JR et al. Proteolysisindependent regulation of the transcription factor Met4 by a single Lys 48-linked ubiquitin chain. Nat Cell Biol 2004; 6: 634-641.

30. Deng L, Wang C, Spencer E, Yang L, Braun A, You J et al. Activation of the IkappaB kinase complex by TRAF6 requires a dimeric ubiquitin-conjugating enzyme complex and a unique polyubiquitin chain. Cell 2000; 103: 351-361.

31. Wang C, Deng L, Hong M, Akkaraju GR, Inoue J, Chen ZJ. TAK1 is a ubiquitin-dependent kinase of MKK and IKK. Nature 2001; 412: 346-351.

32. Shi CS, Kehrl JH. Tumor necrosis factor (TNF)-induced germinal center kinase-related (GCKR) and stress-activated protein kinase (SAPK) activation depends upon the E2/E3 complex Ubc13-Uev1A/TNF receptor-associated factor 2 (TRAF2). J Biol Chem 2003; 278: 15429-15434

33. Kovalenko A, Chable-Bessia C, Cantarella G, Israel A, Wallach D, Courtois G. The tumour suppressor CYLD negatively regulates NF-kappaB signalling by deubiquitination. Nature 2003; 424: 801-805.

34. Zhou H, Wertz I, O'Rourke K, Ultsch M, Seshagiri S, Eby M et al. Bcl10 activates the NF-kappaB pathway through ubiquitination of NEMO. Nature 2004; 427: 167-171.

35. Hofmann RM, Pickart CM. Noncanonical MMS2-encoded ubiquitin-conjugating enzyme functions in assembly of novel polyubiquitin chains for DNA repair. Cell 1999; 96: 645-653.

36. Spence J, Gali RR, Dittmar G, Sherman F, Karin M, Finley D. Cell cycleregulated modification of the ribosome by a variant multiubiquitin chain. Cell 2000; 102: $67-76$.

37. Galan JM, Haguenauer-Tsapis R. Ubiquitin lys63 is involved in ubiquitination of a yeast plasma membrane protein. EMBO J 1997; 16: 5847-5854.

38. Kim HT, Kim KP, Lledias F, Kisselev AF, Scaglione KM, Skowyra D et al. Certain pairs of ubiquitin-conjugating enzymes (E2 s) and ubiquitin-protein ligases (E3 s) synthesize nondegradable forked ubiquitin chains containing all possible isopeptide linkages. J Biol Chem 2007; 282: 17375-17386.

39. Iwai K, Tokunaga F. Linear polyubiquitination: a new regulator of NF-kappaB activation. EMBO Rep 2009; 10: 706-713

40. Jin L, Williamson A, Banerjee S, Philipp I, Rape M. Mechanism of ubiquitin-chain formation by the human anaphase-promoting complex. Cell 2008; 133: 653-665.

41. Polo S, Confalonieri S, Salcini AE, Di Fiore PP. EH and UIM: endocytosis and more. Sci STKE 2003; 2003: re17.

42. Hoege C, Pfander B, Moldovan GL, Pyrowolakis G, Jentsch S. RAD6-dependent DNA repair is linked to modification of PCNA by ubiquitin and SUMO. Nature 2002; 419 135-141.

43. Brooks CL, Li M, Gu W. Monoubiquitination: the signal for p53 nuclear export? Cell Cycle 2004; 3: 436-438

44. Haglund K, Sigismund S, Polo S, Szymkiewicz I, Di Fiore PP, Dikic I. Multiple monoubiquitination of RTKs is sufficient for their endocytosis and degradation. Nat Cell Biol 2003; 5: 461-466.

45. Sloper-Mould KE, Jemc JC, Pickart CM, Hicke L. Distinct functional surface regions on ubiquitin. J Biol Chem 2001; 276: 30483-30489.
46. Ting AT, Pimentel-Muinos FX, Seed B. RIP mediates tumor necrosis factor receptor 1 activation of NF-kappaB but not Fas/APO-1-initiated apoptosis. EMBO J 1996; 15: 6189-6196.

47. Kelliher MA, Grimm S, Ishida $Y$, Kuo F, Stanger BZ, Leder $P$. The death domain kinase RIP mediates the TNF-induced NF-kappaB signal. Immunity 1998; 8: 297-303.

48. Srinivasula SM, Ashwell JD. IAPs: what's in a name? Mol Cell 2008; 30: 123-135.

49. Micheau O, Tschopp J. Induction of TNF receptor I-mediated apoptosis via two sequential signaling complexes. Cell 2003; 114: 181-190.

50. Petersen SL, Wang L, Yalcin-Chin A, Li L, Peyton M, Minna J et al. Autocrine TNFalpha signaling renders human cancer cells susceptible to Smac-mimetic-induced apoptosis. Cancer Cell 2007; 12: 445-456.

51. Barnhart BC, Peter ME. The TNF receptor 1: a split personality complex. Cell 2003; 114 148-150.

52. Wang L, Du F, Wang X. TNF-alpha induces two distinct caspase-8 activation pathways. Cell 2008; 133: 693-703.

53. O'Donnell MA, Legarda-Addison D, Skountzos P, Yeh WC, Ting AT. Ubiquitination of RIP1 regulates an NF-kappaB-independent cell-death switch in TNF signaling. Curr Biol 2007; 17: 418-424.

54. Bertrand MJ, Milutinovic S, Dickson KM, Ho WC, Boudreault A, Durkin J et al. ClAP1 and cIAP2 facilitate cancer cell survival by functioning as E3 ligases that promote RIP1 ubiquitination. Mol Cell 2008; 30: 689-700.

55. Legler DF, Micheau O, Doucey MA, Tschopp J, Bron C. Recruitment of TNF receptor 1 to lipid rafts is essential for TNFalpha-mediated NF-kappaB activation. Immunity 2003; 18: 655-664.

56. Yeh WC, Shahinian A, Speiser D, Kraunus J, Billia F, Wakeham A et al. Early lethality, functional NF-kappaB activation, and increased sensitivity to TNF-induced cell death in TRAF2-deficient mice. Immunity 1997; 7: 715-725.

57. Tada K, Okazaki T, Sakon S, Kobarai T, Kurosawa K, Yamaoka S et al. Critical roles of TRAF2 and TRAF5 in tumor necrosis factor-induced NF-kappa B activation and protection from cell death. J Biol Chem 2001; 276: 36530-36534.

58. Kanayama A, Seth RB, Sun L, Ea CK, Hong M, Shaito A et al. TAB2 and TAB3 activate the NF-kappaB pathway through binding to polyubiquitin chains. Mol Cell 2004; 15: $535-548$.

59. Lee TH, Shank J, Cusson N, Kelliher MA. The kinase activity of Rip1 is not required for tumor necrosis factor-alpha-induced IkappaB kinase or p38 MAP kinase activation or for the ubiquitination of Rip1 by Traf2. J Biol Chem 2004; 279: 33185-33191.

60. Au PY, Yeh WC. Physiological roles and mechanisms of signaling by TRAF2 and TRAF5. Adv Exp Med Biol 2007; 597: 32-47.

61. Takeuchi M, Rothe M, Goeddel DV. Anatomy of TRAF2. Distinct domains for nuclea factor-kappaB activation and association with tumor necrosis factor signaling proteins. J Biol Chem 1996; 271: 19935-19942.

62. Dadgostar $\mathrm{H}$, Cheng $\mathrm{G}$. An intact zinc ring finger is required for tumor necrosis factor receptor-associated factor-mediated nuclear factor-kappaB activation but is dispensable for c-Jun N-terminal kinase signaling. J Biol Chem 1998; 273: 24775-24780.

63. Rothe M, Pan MG, Henzel WJ, Ayres TM, Goeddel DV. The TNFR2-TRAF signaling complex contains two novel proteins related to baculoviral inhibitor of apoptosis proteins. Cell 1995; 83: 1243-1252.

64. Shu HB, Takeuchi M, Goeddel DV. The tumor necrosis factor receptor 2 signal transducers TRAF2 and C-IAP1 are components of the tumor necrosis factor receptor 1 signaling complex. Proc Natl Acad Sci USA 1996; 93: 13973-13978.

65. Wang CY, Mayo MW, Korneluk RG, Goeddel DV, Baldwin Jr AS. NF-kappaB antiapoptosis: induction of TRAF1 and TRAF2 and C-IAP1 and C-IAP2 to suppress caspase-8 activation. Science 1998; 281: 1680-1683.

66. Conze DB, Albert L, Ferrick DA, Goeddel DV, Yeh WC, Mak T et al. Posttranscriptional downregulation of C-IAP2 by the ubiquitin protein ligase c-IAP1 in vivo. Mol Cell Biol 2005; 25: 3348-3356

67. Conte D, Holcik M, Lefebvre CA, Lacasse E, Picketts DJ, Wright KE et al. Inhibitor of apoptosis protein cIAP2 is essential for lipopolysaccharide-induced macrophage survival. Mol Cell Biol 2006; 26: 699-708.

68. Varfolomeev E, Goncharov T, Fedorova AV, Dynek JN, Zobel K, Deshayes K et al. c-IAP1 and C-IAP2 are critical mediators of tumor necrosis factor alpha (TNFalpha)-induced NF-kappaB activation. J Biol Chem 2008; 283: 24295-24299.

69. Mahoney DJ, Cheung HH, Mrad RL, Plenchette S, Simard C, Enwere E et al. Both clAP1 and cIAP2 regulate TNFalpha-mediated NF-kappaB activation. Proc Natl Acad Sci USA 2008; 105: 11778-11783.

70. Habelhah H, Takahashi S, Cho SG, Kadoya T, Watanabe T, Ronai Z. Ubiquitination and translocation of TRAF2 is required for activation of JNK but not of p38 or NF-kappaB. EMBO J 2004; 23: 322-332.

71. Fukushima T, Matsuzawa S, Kress CL, Bruey JM, Krajewska M, Lefebvre $S$ et al. Ubiquitin-conjugating enzyme Ubc13 is a critical component of TNF receptor-associated factor (TRAF)-mediated inflammatory responses. Proc Natl Acad Sci USA 2007; 104: 6371-6376

72. Yamamoto M, Okamoto T, Takeda K, Sato S, Sanjo H, Uematsu S et al. Key function for the Ubc13 E2 ubiquitin-conjugating enzyme in immune receptor signaling. Nat Immunol 2006; 7: 962-970.

73. Yamamoto M, Sato S, Saitoh T, Sakurai H, Uematsu S, Kawai T et al. Cutting edge: pivotal function of Ubc13 in thymocyte TCR signaling. J Immunol 2006; 177: 7520-7524. 
74. Chen ZJ, Parent L, Maniatis T. Site-specific phosphorylation of lkappaBalpha by a novel ubiquitination-dependent protein kinase activity. Cell 1996; 84: 853-862.

75. Opipari Jr AW, Boguski MS, Dixit VM. The A20 cDNA induced by tumor necrosis factor alpha encodes a novel type of zinc finger protein. J Biol Chem 1990; 265: 14705-14708.

76. Dixit VM, Green S, Sarma V, Holzman LB, Wolf FW, O'Rourke K et al. Tumor necrosis factor-alpha induction of novel gene products in human endothelial cells including a macrophage-specific chemotaxin. J Biol Chem 1990; 265: 2973-2978.

77. Lee EG, Boone DL, Chai S, Libby SL, Chien M, Lodolce JP et al. Failure to regulate TNFinduced NF-kappaB and cell death responses in A20-deficient mice. Science 2000; 289: 2350-2354.

78. De Valck D, Jin DY, Heyninck K, Van de Craen M, Contreras R, Fiers W et al. The zinc finger protein A20 interacts with a novel anti-apoptotic protein which is cleaved by specific caspases. Oncogene 1999; 18: 4182-4190.

79. Ina H, Peloponese JM, Verstrepen L, Zapart G, Ikeda F, Smith CD et al. Inflammatory cardiac valvulitis in TAX1BP1-deficient mice through selective NF-kappaB activation. EMBO J 2008; 27: 629-641.

80. Shembade N, Harhaj NS, Liebl DJ, Harhaj EW. Essential role for TAX1BP1 in the termination of TNF-alpha-, IL-1- and LPS-mediated NF-kappaB and JNK signaling. EMBO J 2007; 26: 3910-3922.

81. Shembade N, Harhaj NS, Parvatiyar K, Copeland NG, Jenkins NA, Matesic LE et al. The E3 ligase Itch negatively regulates inflammatory signaling pathways by controlling the function of the ubiquitin-editing enzyme A20. Nat Immunol 2008; 9: 254-262.

82. Shembade N, Parvatiyar K, Harhaj NS, Harhaj EW. The ubiquitin-editing enzyme A2O requires RNF11 to downregulate NF-kappaB signalling. EMBO J 2009; 28: 513-522.

83. Evans PC, Taylor ER, Coadwell J, Heyninck K, Beyaert R, Kilshaw PJ. Isolation and characterization of two novel A20-like proteins. Biochem J 2001; 357 (Part 3): 617-623.

84. Enesa K, Zakkar M, Chaudhury H, Luong LA, Rawlinson L, Mason JC et al. NF-kappa B suppression by the deubiquitinating enzyme cezanne: a novel negative feedback loop in pro-inflammatory signaling. J Biol Chem 2008; 283: 7036-7045.

85. Wright A, Reiley WW, Chang M, Jin W, Lee AJ, Zhang M et al. Regulation of early wave of germ cell apoptosis and spermatogenesis by deubiquitinating enzyme CYLD. Dev Cell 2007; 13: 705-716.

86. Brummelkamp TR, Nijman SM, Dirac AM, Bernards R. Loss of the cylindromatosis tumour suppressor inhibits apoptosis by activating NF-kappaB. Nature 2003; 424: 797-801.

87. Trompouki E, Hatzivassiliou E, Tsichritzis T, Farmer H, Ashworth A, Mosialos G. CYLD is a deubiquitinating enzyme that negatively regulates NF-kappaB activation by TNFR family members. Nature 2003; 424: 793-796.

88. Zhang J, Stirling B, Temmerman ST, Ma CA, Fuss IJ, Derry JM et al. Impaired regulation of NF-kappaB and increased susceptibility to colitis-associated tumorigenesis in CYLDdeficient mice. J Clin Invest 2006; 116: 3042-3049.

89. Massoumi R, Chmielarska K, Hennecke K, Pfeifer A, Fassler R. Cyld inhibits tumor cell proliferation by blocking Bcl-3-dependent NF-kappaB signaling. Cell 2006; 125: 665-677.

90. Xue L, Igaki T, Kuranaga E, Kanda H, Miura M, Xu T. Tumor suppressor CYLD regulates JNK-induced cell death in Drosophila. Dev Cell 2007; 13: 446-454.

91. Hsu H, Xiong J, Goeddel DV. The TNF receptor 1-associated protein TRADD signals cell death and NF-kappa B activation. Cell 1995; 81: 495-504.

92. Pobezinskaya YL, Kim YS, Choksi S, Morgan MJ, Li T, Liu C et al. The function of TRADD in signaling through tumor necrosis factor receptor 1 and TRIF-dependent Toll-like receptors. Nat Immunol 2008; 9: 1047-1054.

93. Ermolaeva MA, Michallet MC, Papadopoulou N, Utermohlen O, Kranidioti K, Kollias G et al. Function of TRADD in tumor necrosis factor receptor 1 signaling and in TRIFdependent inflammatory responses. Nat Immunol 2008; 9: 1037-1046.
94. Zuccato E, Blott EJ, Holt O, Sigismund S, Shaw M, Bossi G et al. Sorting of Fas ligand to secretory lysosomes is regulated by mono-ubiquitylation and phosphorylation. J Cell Sci 2007; 120 (Part 1): 191-199.

95. Budd RC, Yeh WC, Tschopp J. cFLIP regulation of lymphocyte activation and development. Nat Rev Immunol 2006; 6: 196-204

96. Salvesen GS, Duckett CS. IAP proteins: blocking the road to death"s door. Nat Rev2002; 3: $401-410$.

97. Jost PJ, Grabow S, Gray D, McKenzie MD, Nachbur U, Huang DC et al. XIAP discriminates between type I and type II FAS-induced apoptosis. Nature 2009; 460: 1035-1039.

98. Chang L, Kamata H, Solinas G, Luo JL, Maeda S, Venuprasad K et al. The E3 ubiquitin ligase itch couples JNK activation to TNFalpha-induced cell death by inducing c-FLIP(L) turnover. Cell 2006; 124: 601-613.

99. Gao M, Labuda T, Xia Y, Gallagher E, Fang D, Liu YC et al. Jun turnover is controlled through JNK-dependent phosphorylation of the E3 ligase Itch. Science 2004; 306: 271-275.

100. Muppidi JR, Tschopp J, Siegel RM. Life and death decisions: secondary complexes and lipid rafts in TNF receptor family signal transduction. Immunity 2004; 21: 461-465.

101. Wagner S, Carpentier I, Rogov V, Kreike M, Ikeda F, Lohr F et al. Ubiquitin binding mediates the NF-kappaB inhibitory potential of ABIN proteins. Oncogene 2008; 27: 3739-3745

102. Oshima S, Turer EE, Callahan JA, Chai S, Advincula R, Barrera J et al. ABIN-1 is a ubiquitin sensor that restricts cell death and sustains embryonic development. Nature 2009; 457: 906-909.

103. Jin Z, Li Y, Pitti R, Lawrence D, Pham VC, Lill JR, Ashkenazi A. Cell 2009; 137: 721-735.

104. Crook NE, Clem RJ, Miller LK. An apoptosis-inhibiting baculovirus gene with a zinc fingerlike motif. J Virol 1993; 67: 2168-2174.

105. Ditzel M, Wilson R, Tenev T, Zachariou A, Paul A, Deas E et al. Degradation of DIAP1 by the N-end rule pathway is essential for regulating apoptosis. Nat Cell Biol 2003; 5 467-473

106. Ditzel M, Broemer M, Tenev T, Bolduc C, Lee TV, Rigbolt KT et al. Inactivation of effector caspases through nondegradative polyubiquitylation. Mol Cell 2008; 32: 540-553.

107. Vaux DL, Silke J. IAPs, RINGs and ubiquitylation. Nat Rev 2005; 6: 287-297.

108. Eckelman BP, Salvesen GS, Scott FL. Human inhibitor of apoptosis proteins: why XIAP is the black sheep of the family. EMBO Rep 2006; 7: 988-994.

109. Gyrd-Hansen M, Darding M, Miasari M, Santoro MM, Zender L, Xue W et al. IAPs contain an evolutionarily conserved ubiquitin-binding domain that regulates NF-kappaB as well as cell survival and oncogenesis. Nat Cell Biol 2008; 10: 1309-1317.

110. Blankenship JW, Varfolomeev E, Goncharov T, Fedorova AV, Kirkpatrick DS, IzraelTomasevic A et al. Ubiquitin binding modulates IAP antagonist-stimulated proteasoma degradation of C-IAP1 and C-IAP2(1). Biochem J 2009; 417: 149-160.

111. Breitschopf K, Zeiher AM, Dimmeler S. Ubiquitin-mediated degradation of the proapoptotic active form of bid. A functional consequence on apoptosis induction. J Biol Chem 2000; 275: 21648-21652.

112. Li B, Dou QP. Bax degradation by the ubiquitin/proteasome-dependent pathway: involvement in tumor survival and progression. Proc Natl Acad Sci USA 2000; 97: 3850-3855.

113. Liu FT, Agrawal SG, Gribben JG, Ye H, Du MQ, Newland AC et al. Bortezomib blocks Bax degradation in malignant $B$ cells during treatment with TRAIL. Blood 2008; 111: 2797-2805

114. Yu M, Liu FT, Newland AC, Jia L. The alpha- 5 helix of Bax is sensitive to ubiquitindependent degradation. Biochem Biophys Res Commun 2008; 371: 10-15.

115. Fu NY, Sukumaran SK, Kerk SY, Yu VC. Baxbeta: a constitutively active human Bax isoform that is under tight regulatory control by the proteasomal degradation mechanism. Mol Cell 2009; 33: 15-29. 